This is the peer reviewed version of the following article:Economic Record Volume 84, Issue Supplement s1, pages S17-S31, September 2008. which has been published in final form at http://dx.doi.org/10.1111/j.14754932.2008.00480.x This article may be used for non-commercial purposes in accordance With Wiley Terms and Conditions for self-archiving' 


\title{
Choices and Constraints over Retirement Income Streams: Comparing
}

\section{Rules and Regulations *}

\author{
Hazel Bateman \\ School of Economics, University of New South Wales \\ Susan Thorp \\ School of Finance and Economics, University of Technology, Sydney
}

\begin{abstract}
The new Simplified Superannuation regulations for Australian superannuation provide tax concessions to retirement income streams which comply with legislated minimum drawdown rules. We evaluate these new drawdown rules against four alternatives, including three formula-based 'rules of thumb' used by financial planners. We find that the new regulations are a substantial improvement on the previous rules for allocated pensions and, when compared with the formula-based rules, are a good compromise in terms of simplicity, adequacy and risk. We also find that welfare is lower for most individuals who follow the Simplified Superannuation rules compared with welfare under an optimal path or a simple fixed percentage drawdown rule, but that outcomes could be improved through a further simplification of the new rules.
\end{abstract}

\section{Key Words:}

Retirement income policies, retirement income streams, private pensions, superannuation

JEL Codes:

G23, G28, H55, J26, J32

Possible running head:

Retirement Income Stream Regulations

* We thank participants at the $12^{\text {th }}$ Melbourne Money and Finance Conference - Wealth Management: Trends and Issues, (May 25-26 2007) and the $36^{\text {th }}$ Annual Conference of Economists (September 24-26 2007), and anonymous reviewers for useful comments. Financial support from ARC Discovery Grant DP0556775 is gratefully acknowledged. 


\section{Corresponding author}

Hazel Bateman

School of Economics, University of New South Wales

Postal Address: School of Economics, University of new South Wales, Sydney 2052

Email Address: h.bateman@unsw.edu.au

Phone: 0293853096

Fax: 0293136337 


\section{Choices and Constraints over Retirement Income Streams: Comparing Rules and Regulations}

\section{Introduction}

The past two decades have witnessed substantial changes to retirement savings policies and products around the world, as policy makers and the wealth management industry have attempted to address the retirement needs of ageing populations. Retirement income reforms in Australia, in the form of the Superannuation Guarantee and incentives to make voluntary contributions, have resulted in a huge increase in the coverage of superannuation, from less than 50 per cent of employees in the mid 1980s to close to 100 per cent of full time employees by 2007. However, despite the imminent retirement of the first of the baby boomers, far less attention has been paid to policy and product development to enable an orderly drawdown of savings in retirement than to enabling accumulation. ${ }^{1}$

In Australia, in the absence of compulsion, successive governments have attempted to encourage the take-up of retirement income streams through incentives in the tax system and concessions under the Age Pension means tests. While these incentives and concessions have been continually modified over the past twenty years or so, they appear to have done little to address Australian retirees' preference for lump sum benefits.

The Simplified Superannuation measures introduced in the 2006-07 Commonwealth Budget ${ }^{2}$ have changed the constraints and concessions for Australian superannuants yet again. Retirees aged 60 and over are now exempt from tax on all retirement benefits ${ }^{3}$ - whether taken as a lump sum or an income stream - and all retirement income streams are subject to 
the same Age Pension income and assets tests, irrespective of income stream type. As well, where the drawdown pattern complies with a legislated schedule of minimum percentages of account balance, earnings on the underlying assets are also free of tax. These new income streams are called 'account-based pensions' and the revised drawdown schedule replaces the previous minimum and maximum drawdown limits for allocated pensions. The new rules appear to be designed to discourage retirees from using tax-concessional retirement savings for storing up bequests, while at the same time giving some guidance on a prudent spending plan (Bateman and Kingston, 2007).

Economic theory has long held that optimal drawdown plans in retirement will differ according to the preferences of each individual and the risks they face ${ }^{4}$, while the financial planning industry has frequently proposed simple 'rules of thumb' as approximations to more complicated dynamic plans. Typical rules of thumb relate the drawdown of the retirement accumulation to the age or life expectancy of the retiree, while others advocate a fixed (or escalated) drawdown of the retirement accumulation in an attempt to mimic the payment schedule of a life annuity In this study we investigate the benefits and risks of the new minimum drawdown requirements under Simplified Superannuation and compare them with outcomes under the previous legislated limits for allocated pensions and a range of simple 'rules of thumb', as well as theoretically optimal paths. We do this for retirees holding their retirement savings in typical investment plans, matching the most common offerings of allocated pension and superannuation investments, and accounting for longevity patterns drawn from the latest Australian Life Table projections.

We find that following the legislated minimum drawdown plan under Simplified Superannuation means lower welfare for most individuals when compared with following an 
optimal path or a simple fixed percentage drawdown rule. We also show that the regulations are a binding constraint on optimal drawdown plans, but the reductions in welfare when compared with the unconstrained plans are fairly small. Overall the new Simplified Superannuation regulations offer a substantial improvement over the previous allocated pension minimum valuation factors and are a good compromise in terms of simplicity, adequacy and risk. We conclude that welfare could be further improved with a minor simplification of the new drawdown rule.

We begin with a survey of retirement income stream products and policies in Australia. We then evaluate the new minimum drawdown requirements for account-based pensions under Simplified Superannuation against possible alternatives, using the criteria of simplicity, adequacy, risk and consumer welfare. We conclude by exploring ways to further improve the new rules and indicate avenues for future research.

\section{Retirement Income Products and Policies in Australia}

The policy framework for retirement income streams in Australia has been evolving since the decision in the late 1970s to concentrate on encouraging (and later mandating) privately managed saving for retirement, rather than introduce the then popular OECD-style system of earnings-related public pensions (Bateman, Kingston and Piggott, 2001). However, the decision to mandate retirement saving did not include (and has not subsequently included) mandatory retirement incomes. Instead, retirement income policy (as opposed to retirement saving policy) has been the subject of a succession of reforms and changes as attempts have been made to encourage the voluntary take-up of income streams with particular features. These reforms commenced in the 1980s with the decision to exempt from tax the earnings of assets underlying certain types of annuities and have evolved since then to include tax and 
Age Pension means test concessions for a wide range of income streams. The most recent changes are the Simplified Superannuation reforms announced in the 2006-07 Commonwealth Budget and implemented throughout 2007, which were introduced with the stated aim of simplifying retirement income stream policies and products (Australian Treasury, 2006a and Australian, Treasury, 2006b).

An important initiative in the 1990s was the introduction of a statutory framework for a phased withdrawal product - called an allocated pension. ${ }^{5}$ As compared to an annuity, the purchaser retiree retains ownership of the capital sum, is able to choose the underlying asset allocation and has some discretion over the drawdown pattern. Under the pre-2006 Budget rules, drawings from allocated pensions had to be made at least annually and were subject to legislated minimum and maximum limits (which differed by the age of the account holder). ${ }^{6}$

At the time of the 2006 Budget, the regulatory framework recognized four types of retirement income streams: lifetime annuities, term certain annuities, allocated pensions (and annuities), and a hybrid product (introduced in 2004), called a term allocated pension (TAP) or market-linked income stream. ${ }^{7}$ These alternative products provide different benefits to Australian retirees. Lifetime annuities insure against longevity risk and investment risk and can be designed to address inflation risk. However, pricing issues and conservative asset allocations may compromise adequacy. Life expectancy term annuities have similar attributes, with the exception of longevity risk, while allocated pensions and TAPs have the possibility of higher expected returns, but leave retirees exposed to investment risk and longevity risk. 
The pre-2006 Budget approach provided, through the tax system and under the Age Pension means tests, the strongest incentives to purchase lifetime annuities, life expectancy term annuities and TAPs. The centerpiece was a 50 per cent exemption from the Age Pension assets test (which itself had been reduced from a 100 per cent exemption in 2004), and, in addition, income streams defined as ‘complying annuities' were free of tax on the earnings of underlying assets. Further, retirees who took certain types of income streams were eligible for a higher pension reasonable benefit limit (RBL) and a 15 per cent annuity rebate. ${ }^{8}$

The tax and Age Pension means tests treatment of each of these retirement income types, before and after the implementation of Simplified Superannuation, are summarized in Table 1.

<insert Table 1 about here>

Despite these incentives, the overwhelming preference of those Australian retirees who take income streams rather than lump sums at retirement, has been to purchase allocated pensions ${ }^{9}$ or account-based pensions as they are now known. The market share for new purchases of the four types of retirement income streams over the period 1999 to 2007 is illustrated in Figure 1.

$<$ insert Figure 1 about here $>$

In the September quarter 2007, allocated pensions accounted for 88.2 per cent of new purchases of retirement income streams (by dollar amount sales). The remainder comprised 5.8 per cent for term annuities, 5.9 per cent for TAPs and less than 0.1 per cent for life annuities. 
Figure 1 clearly illustrates the impact of changes to the tax rules, Age Pension means tests and regulatory environment on the take-up of the different types of income streams. For example, the announcement in the May 2004 Budget of a plan to reduce the assets test preference for lifetime and life expectancy annuities (from a 100 per cent to a 50 per cent exemption) from 20 September of that year saw an increase in sales of these products in the September quarter 2004, followed by a significant fall in subsequent quarters. This change, in conjunction with legislative approval for a market linked annuity product (called a term allocated pension or TAP), led to a fall in the market share of life annuities from around three per cent to less than 0.2 per cent

Under Simplified Superannuation, the rules and regulations for the different types of retirement income streams were streamlined. All superannuation benefits are now tax free (for retirees aged 60 and over $^{10}$ ) and retirement income streams that meet minimum standards accumulate free of tax. Since 20 September 2007, the Age Pension means tests have applied equally (and fully) to all types of retirement income streams.

The new minimum standards for account-based pensions include the drawdown of a minimum amount at least annually, no residual capital value and transfer only upon death. ${ }^{11}$ The minimum drawdown payments are defined as a percentage of the remaining account balance and vary by age as summarized in Table 2 below. ${ }^{12}$ These rules for account-based pensions replace the previous minimum and maximum limits for allocated pensions.

$<$ insert Table 2 about here $>$ 
In the analysis that follows, we evaluate these new drawdown rules against a number of alternatives using criteria to assess simplicity, adequacy, risk, and consumer welfare as measured by a utility function.

\section{Evaluating Alternative Drawdown Rules}

\section{(i) Alternative Drawdown Rules}

We compare the minimum drawdown payouts for account-based pensions under Simplified Superannuation against four alternative drawdown rules, including the previous legislated minimum payments for allocated pensions and three standard 'rules of thumb' used by financial planners where there are no statutory requirements. Typically these 'rules of thumb' are simple formulas which may relate the drawdown of the retirement accumulation to the age or life expectancy of the retiree, or perhaps attempt to mimic the payment schedule of a life annuity In summary, the five rules under consideration comprise two statutory rules and three formula-based rules ${ }^{13}$, as follows:

- The minimum drawdown requirements for account-based pensions under Simplified Superannuation (referred to from now on as the 'new legislated minimum'). The minimum drawdown varies by age from four per cent of the outstanding account balance for those aged less than 65 to 14 per cent for retirees aged 95 and over (see Table 2);

- The pre-2006 Budget legislated minimum payments for allocated pensions (referred to from now on as the 'previous legislated minimum'). The minimum (and maximum) drawdowns are determined by age-based statutory Pension Valuation Factors - where, for example, the minimum payment limit for a 65 year old would be the account balance

divided by the minimum Pension Valuation Factor for a beneficiary aged 65; ${ }^{14}$ 
- A fixed percentage rule: where a constant fraction of the outstanding account balance is withdrawn each period;

- A $1 / T$ rule: where $T=N-(x+t)$. That is, the denominator $T$ is the oldest age in mortality table $(N)$ less the retirees current age $(x+t)$, where $x$ is the age at retirement and $t$ is the years since retirement $(t=1 \ldots . N-x)$;

- A $1 / E(L)$ rule: where the denominator $E(L)$ is life expectancy at the retiree's current age (age $x+t){ }^{15}$

A standard metric for comparison of alternative drawdown rules is the benefit/wealth ratio $(\omega)$. For each year in retirement, $t$, this is defined as $\omega_{\tau}=B_{t} / V_{t}$, where $B_{t}$ is the payout at time $t$ and $V_{t}$ is equal to the account balance (prior to payment of the benefit) at time $t$. For the fixed percentage rule we set the drawdown rate equal to the first year payout that the retiree would receive if they purchased a single life annuity in the current market using their retirement accumulation (as a percentage of the retirement accumulation). We refer to this from now on as the 'benchmark life annuity' and the annual payment as the 'benchmark annuity payout'. Using current annuity prices, we estimate the benefit/wealth ratio for the 'benchmark life annuity’ at 6.0 per cent for females and 6.1 per cent for males. ${ }^{16}$

Figure 2 illustrates the benefit/wealth ratio paths (over the potential retirement period from age 60 to age 108) for each of the five drawdown rules under consideration. The results we present here, and from now on, are for a hypothetical female in retirement. As noted in Horneff et al. (2007) it is appropriate to focus on the case of the female retiree as longevity risk is more important for women than for men because they live longer.

$<$ insert Figure 2 about here $>$ 
The paths of the benefit/wealth ratios (as the retirees age) differ substantially between the alternative drawdown rules. By definition, the benefit/wealth ratio for the fixed percentage rule remains at 6 per cent throughout the entire period of potential retirement. Similiarly, the new legislated minimum rules retain some simplicity with only seven different drawdown ratios (ranging from 4 per cent to 14 per cent) over the entire period of potential retirement. By comparison, the paths of the benefit/wealth ratios for the remaining drawdown rules are more complex and the benefit/wealth ratio increases continuously throughout the period of potential retirement. The benefit/wealth ratio for the $1 / T$ rule (which is based on the age of the retiree) commences at two per cent at age 60 and increases at every age, reaching 100 per cent at the oldest age in the Australian Life Tables The $1 / E(L)$ rule (which is based on the life expectancy of the retiree) generates a gradual increase in the benefit/wealth ratio from 3.7 per cent to 87 per cent, while the drawdowns under the previous legislated minimum increase from 5.8 per cent of the account balance at age 60 to 28.6 per cent of the account balance at age 98 and remain constant thereafter.

Benefit/wealth ratios provide valuable information on the pattern of drawdowns by age, and the complexity of the different rules (in terms of reasonably constant or continually changing drawdown percentages), However, they provide no indication of the adequacy of these drawdowns rules to fund ongoing retirement expenses or of the risk associated with the underlying asset allocations. Nor do they assess how a retiree might evaluate the drawdown rules after taking account of risk aversion and time preference.

\section{(ii) Portfolio Return and Volatility}

One of the features of products allowing periodic drawdowns, such as Australia's previous allocated pensions and the new account-based pension products, as compared with standard 
annuity products, is the ability to choose the asset allocation of the portfolios underlying the income streams. For example, in 2007 HESTA, one of Australia's largest industry superannuation funds offered choice of nine investment options for their new account-based pension product. These included five portfolios comprising different combinations of Australian shares, international shares, property, alternative investments, Australian fixed interest, international fixed interest and cash, and four portfolios which include socially

responsible investments (SRIs) in the asset mix. ${ }^{17}$ In order to realistically simulate and compare the alternative drawdown rules, we have constructed five 'representative' investment portfolios for our hypothetical account-based pension products. These are designated High Growth, Growth, Balanced, Conservative and Capital Stable and comprise different proportions of Australian shares, international shares, Australian property, Australian fixed interest and cash. The methodology underlying the construction of these portfolios as well as the portfolio returns and volatilities is set out in Appendix 1.

We can now combine the drawdown patterns, as illustrated by the benefit/wealth ratios, with our representative portfolios to evaluate the alternative drawdown rules.

\section{(iii) Assessment of the Alternative Drawdown Rules for Retirement Incomes}

We assess the five alternative drawdown rules using the criteria of simplicity, adequacy, risk and consumer welfare as measured by a utility function. Initially we assume that the underlying assets are held in a balanced portfolio (an assumption we later relax). As well, we ignore possible taxes on the earnings of the underlying assets and do not take account of interactions with the public Age Pension. ${ }^{18}$ 
Simplicity: Our gauge of simplicity is a clearly defined schedule of drawdown percentages, as indicated by the benefit to wealth ratios discussed earlier and summarized in Figure 2 . Here the fixed percentage rule dominates (by definition) followed closely by the seven-phase minimum drawdown rule introduced as part of the Simplified Superannuation reforms. For the other rules evaluated here, the benefit to wealth ratio is different for every annual drawdown.

Adequacy: Our metric for adequacy is 'expected benefit'. This is defined as the annual expected benefit from a particular drawdown rule as a proportion of the annual payment from the 'benchmark life annuity'. Figure 3 shows expected benefit paths for each of the five drawdown rules, assuming that the individual survives to age 108, and the underlying assets are invested in the balanced portfolio plan.

$<$ insert Figure 3 about here $>$

As shown in Figure 3, there are significant differences in the expected benefit by drawdown rule and age. The expected benefit under the fixed percentage rule starts off at 100 per cent of the benchmark life annuity (by design) and then gradually increases with age (as the rate of return on the underlying assets exceeds that on the lifetime annuity). The expected benefit under the $1 / T$ rule is the lowest of the five rules at age 60 , but continues to rise by age, reaching 200 per cent of the benchmark annuity when the retiree is in her mid-80s, and 500 per cent if she is still alive in her mid-90s. This happens because the rule results in small payouts in the early years, leading to higher accumulations to be paid out in later years. Finally, the $1 / E(L)$ rule initially provides a lower expected benefit of around 60 per cent of 
the benchmark annuity at age 60, which rises to peak at 235 per cent of the benchmark annuity at age 85, and then falls rapidly at very old ages if the pensioner is still alive.

Of the statutory rules, the path of expected benefits under the previous legislated minimum tracks the $1 / E(L)$ rule quite closely, although it is higher for the first 13 years of retirement and peaks at around 160 per cent of the benchmark annuity at age 80 (under our assumptions). The Simplified Superannuation legislated minimum generates a path of expected benefits below the benchmark annuity (and the fixed percentage rule) for the first six years of retirement. Thereafter, the expected benefits increase as a proportion of the benchmark annuity as the higher percentage drawdown takes effect, peaking at around 260 per cent of the benchmark annuity at age 95. Payouts under this rule then fall back to around 100 per cent of the benchmark annuity for those still alive after age 100 .

The impact of changing the underlying asset allocation from a balanced portfolio to the alternatives of high growth, growth, conservative and capital stable, is to change the level of expected benefits, but not the rankings of the alternative drawdown rules by age. The expected benefit paths for the Simplified Superannuation drawdown rules under the five illustrative portfolio allocations are illustrated in Figure 4. These estimates show, for example, that for retirees still alive at age 85, the capital stable portfolio delivers a drawdown 60 per cent higher than the benchmark annuity, compared with 97 per cent higher for the conservative portfolio, 130 per cent higher under the balanced portfolio, 164 per cent under the growth portfolio and 172 per cent higher under the high growth portfolio.

$<$ insert Figure 4 about here $>$ 
Risk: As a measure of risk, we construct a metric representing a 'worst case scenario' for each drawdown rule, given an underlying asset allocation. More precisely our metric is defined as the dollar amount of retirement income represented by the first percentile ${ }^{19}$ of the payout distribution, as generated using the rates of return and standard deviations estimated for the illustrative portfolios (see Table A2), as a proportion of the annual payment from the 'benchmark life annuity' ${ }^{20}$ Figure 5 illustrates this worst case scenario for each of the five drawdown rules under consideration where the retirement accumulation is invested in a balanced portfolio. With the exception of the $1 / E(L)$ rule, where the minimum benefit reaches the benchmark annuity by age 77, all of the worst case scenarios are below the benchmark annuity payouts until retirees reach their mid-80s.

$<$ insert Figure 5 about here $>$

In the early years of retirement (for retirees in their 60s) the probable minimum benefits are quite similar under both the previous legislated minimum and the fixed percentage rule, but are lower for both the $1 / E(L)$ rule and the new rules under Simplified Superannuation. For the fixed percentage rule and the previous legislated minimum rule, the probable minimum benefit is less than the benchmark annuity payout for the entire period of potential retirement (from age 60 to age 108 in our analysis).

On the other hand, the probable minimum payments under the $1 / T$ rule start at very low levels (of less than 50 per cent of the benchmark annuity payout) in the early years of retirement but increase rapidly in later retirement to over 300 per cent of the benchmark annuity for those who live into their 90s. Where the retirement accumulation is invested in a 
balanced portfolio, the Simplified Superannuation rules result in a minimum benefit well in excess of the benchmark annuity for retirees who live past their mid 80s.

As with expected benefits, the impact of altering the underlying portfolio allocation is to change the level of the minimum benefit, but not the rankings by age of the alternative drawdown rules.

Consumer welfare: Finally, to take account of risk aversion and the time preference of the retirees, we evaluate the five drawdown rules using a utility framework.

Following the approach taken in Horneff et al. (2007) we adopt CRRA preferences with uncertainty over survival and assume that the retiree's objective function $U$ is defined over total benefits received and a bequest left at death. The benefits received are the minimum annual payments under the alternative drawdown rules. It is assumed that these benefits account for total income in each period and are entirely consumed in the corresponding period.

Our assumed utility function $(U)$, takes the form

$U=E \sum_{t=0}^{T}\left\{\left(\prod_{i=0}^{t-1} p_{x+t}\right)\left[\beta^{t} \cdot p_{x+t}\left(\frac{B_{t}^{1-\gamma}}{1-\gamma}\right)+k \beta^{t} \cdot\left(1-p_{x+t}\right)\left(\frac{V_{t}^{1-\gamma}}{1-\gamma}\right)\right]\right\}$

where $\beta$, an annual discount factor representing the rate of time preference of the retiree, is set to 0.96 (following previous analysis - Horneff et al. 2007, Blake et al, 2003), $k$ is the strength of the bequest motive (ranging from 0 to 1 ), $p_{x+t}$ is the probability that a female of age $x+t$ survives one more year ${ }^{21}$ and the individual's coefficient of relative risk aversion is 
represented by $\gamma$, which ranges from 0.5 to 8 in this analysis. ${ }^{22}$ As indicated earlier, the nominal benefit from a drawdown plan in period $t$ is given by $B_{t}$ and the value of assets remaining in the account is $V_{t}$.

As with our earlier analysis we initially assume that the assets underlying the retirement income stream are invested in a balanced portfolio. To compare the utility of the different rules, we calculate the expected lifetime utility (using equation 1 ) for each of the five alternative drawdown rules, for levels of risk aversion ranging from 0.5 to 8 . Initially we assume no bequests, so the bequest weight, $k$, is set at 0 . We then translate each utility level into an equivalent annuity income stream for life and express this as a proportion of the 'benchmark annuity'. The annuity equivalent income stream can be interpreted as the constant nominal lifetime income stream that would provide the same level of utility to the retiree as the drawdown in question. We also compute the optimal path of drawdown using dynamic programming for each level of risk aversion, to provide a point of comparison with arbitrarily chosen paths. ${ }^{23}$

Differences in welfare derived from a particular drawdown path are illustrated in Figure 6. For each of the five withdrawal rules (and the optimal path), we graph the annuity equivalent income stream as a proportion of the benchmark annuity stream, for levels of risk aversion from 0.5 to 8 .

$<$ insert Figure 6 about here> 
The results show the importance of risk aversion in determining the preferred drawdown rule. ${ }^{24}$ After the optimal paths, which are most preferred for any level of risk aversion by construction, the $1 / E(L)$ rule and the previous legislated minimum are most preferred for females with low levels of risk aversion, but least preferred for females with medium to high levels of risk aversion, while the $1 / T$ rule is least preferred for females with low levels of risk aversion and then ranks mid-range as levels of risk aversion increase. The fixed percentage rule dominates all other strategies for female retirees with medium and high levels of risk aversion. ${ }^{25}$ The new rules for account-based pensions under Simplified Superannuation, rank mid-range across the spectrum of risk tolerance, while the previous legislated minimum drawdown for allocated pensions ranks poorly, except for females with very low levels of risk aversion.

So far we have assumed that the underlying assets are held in a balanced portfolio. The impact of the alternative portfolio allocations on consumer preferences is to change the size of the certainty equivalent annuity estimates (as a proportion of the benchmark annuity), but not the rankings by risk tolerance of the alternative drawdown rules. As would be expected, the path of certainty equivalent annuity estimates (as one moves from individuals with low to high risk tolerance) become flatter as one changes the underlying asset allocation from high growth, to growth, to balanced, conservative, and then capital stable.

Finally, we also tested for the sensitivity of our results if we relaxed the assumption of no bequests (by changing $k$ from 0 to 1 ). Overall, our results do not change significantly if we relax the assumption of no bequests. 


\section{Discussion}

We have assessed five alternative drawdown rules in terms of simplicity, adequacy, risk and consumer preferences. A key finding is that the different drawdown rules perform differently under each of the criteria for assessment, for retirees at different ages and for different levels of risk aversion. Further, as one would expect, modifying the underlying asset allocation changes the drawdown amounts, but not the ranking of the alternative drawdown rules under each of the assessment criteria.

In summary:

- The benefit/wealth ratios provide some indication of simplicity - where simplicity is defined as clearly identified drawdown percentages. The fixed percentage rule ranks first (by assumption) closely followed by the new legislated minimum rules.

- Under the metric for expected benefit - expected drawdown as a percentage of the 'benchmark annuity payment' - the previous legislated minimum for allocated pensions performs well for younger retirees, the $1 / T$ rule does well for older retirees, while the fixed percentage rule and the new Simplified Superannuation rules for account-based pensions do quite well for retirees of all ages.

- Similarly, under the metric for risk - the minimum expected benefit defined as the dollar amount of retirement income represented by the first percentile of the payout distribution as a proportion of the 'benchmark annuity payment' - the previous legislated minimum rules for allocated pensions perform best for younger retirees, the $1 / T$ does best for older retirees, and the Simplified Superannuation rules have reasonably high minimum benefits for all ages. However, where the accumulation is invested in a balanced portfolio the 
probable minimum benefit under the fixed percentage rule, is below the benchmark annuity over the entire period of retirement.

- The analysis of consumer welfare indicates that the fixed percentage rule dominates the new legislated minimum drawdowns for account-based pensions at high levels of risk aversion while the $1 / E(L)$ is preferred for females with a low level of risk aversion. The optimal path is (by construction) preferred to all rules for any level of risk aversion, with the fixed percentage rule preferred next for all except those with low levels of risk aversion.

Overall, the new legislated minimum drawdown rules for account-based pensions under Simplified Superannuation perform reasonably well under all criteria, and offer a substantial improvement over the previous allocated pension minimum drawdown limits. However, the fixed percentage rule also performs well under all criteria and is preferred to the illustrative drawdown rules we consider for all except retirees with high tolerance to risk. This conclusion was also reached in Horneff et al. (2007) in a similar analysis motivated by the private pension arrangements in the US and Germany.

So far we have treated the minimum drawdown regulations as if they were fixed. We note, however, that the new minimum drawdown rules are not upper bounds on withdrawals, and retirees are free to make drawdowns of more than the minimum if they wish. In this context we investigate the case where the fixed percentage or optimal drawdown rules are followed, except where they breach the new rules - in which case the new legislated minimum rules apply. 
We focus on the optimal path and the fixed percentage rule because they are the most preferred of the alternative drawdown rules. For each we compare the certainty equivalent annuity (as a proportion of the benchmark annuity) for the so-called 'unconstrained' drawdowns (as discussed above and set out in Figure 6), with the certainty equivalent annuity proportions where the drawdowns are ‘constrained’ by the new rules.

Our results, summarized in Figure 7, show that utility improves slightly across all levels of risk aversion where the drawdown patterns under the fixed percentage rule are constrained by the new seven-phase drawdown rules. However, a retiree following an optimal path is made slightly worse off by having to abide by the minimum drawdown at higher levels of risk aversion. The reason for the improvements in welfare when the fixed percentage rule is constrained by the new minimum regulations is that the retiree is compelled to consume at a faster rate towards the end of life by the regulations, a pattern which mimics more closely the optimal path. Similarly, the fixed percentage rule increases consumption in early retirement compared with the new legislated minimum rules, again aligning closer to the optimal path. The combination of both rules improves welfare for most consumers. Slightly lower utility attaches to the constrained optimal path compared with the unconstrained path because the new legislated minimum rules compel very risk-averse retirees to consume slightly faster than they would like at older ages.

<insert Figure 7 about here $>$

An outcome of this analysis is that we can 'back-out' the drawdown patterns implied by the 'constrained' paths. In Figure 8 we compare the implied drawdown patterns under the 'constrained' optimal path for three illustrative levels of risk aversion - set at relative risk 
aversion of two, five and seven - with the implied drawdown pattern under the 'constrained' fixed percentage rule and the new seven-phase drawdown rule for account-based pensions under Simplified Superannuation. As with our earlier analysis we assume that the underlying assets are invested in a balanced portfolio and there are no bequests.

$<$ insert Figure 8 about here $>$

This comparison indicates that the implied drawdowns under the 'constrained' optimal path are reasonably insensitive to levels of risk aversion for younger retirees, but that risk averse older retirees draw down at a slower rate than their more risk tolerant counterparts. A close examination of the graph shows that the regulatory minimum constraint is binding for the more risk averse from ages in the mid-80s to the late 90s.

A feature of all three of the illustrative implied optimal drawdown rules, is that the drawdown rule (that is, the percentage of the retirement accumulation drawn down) is different in every period. This outcome can be compared with the seven-phase drawdown pattern under the new legislated minimum drawdown rules for account-based pensions, and the implied drawdown pattern under the constrained fixed percentage alternative which compress into a five-phase rule - six per cent of the account balance if under age 80 , seven per cent for ages 80-84, nine per cent for ages 85-89, 11 per cent for ages $90-94$ and 14 per cent thereafter.

\section{Concluding Comments}

In sum, our analysis indicates that the new legislated minimum drawdown rules for accountbased pensions are not only a significant improvement on the previous drawdown limits for

allocated pensions, but perform well against a range of alternative rules. However, we find 
that welfare can be improved for all retirees where the current seven-phase drawdown rule is further simplified to a five-phase rule, under which retirees are required to draw down their retirement accumulation at a faster rate during their early years of retirement - as indicated by the 'constrained fixed percentage' path in Figure 8.

So far we have ignored taxes and the interaction of the amounts drawn down with the public Age Pension. While superannuation benefits are tax free (for retirees age 60 and above), the earnings on the underlying assets are only free of tax where the legislated minimum drawdown requirements are met. In circumstances where the legislated minimum drawdown rules are not met, the effective tax rate applying to the earnings of the underlying assets will then depend upon the particular portfolio allocation (due to the working of the imputation system). As well, although the Age Pension means tests now apply equally to all types of retirement income streams, the availability of a public Age Pension (which has the features of an indexed life annuity) would influence the estimates of utility.

Overall, our analysis suggests that welfare could be further improved with even more simplification of Simplified Superannuation. Future research will explore whether these results still hold when account is taken of taxes and public Age Pension interactions. 


\section{REFERENCES}

Australian Treasury (2006a), A Plan to Simplify and Streamline Superannuation - Detailed Outline, May 2006.

Australian Treasury (2006b), A Plan to Simplify and Streamline Superannuation - Outcomes of Consultation, September 2006.

Bateman, H. and Kingston, G. (2007), 'Superannuation and Personal Income Tax Reform’, Australian Tax Forum, 22, 137-163

Bateman, H., Kingston, G., and Piggott, J. (2001), Forced Saving: Mandating Private Retirement Incomes, Cambridge University Press.

Blake, D., Cairns, A.J.G. and Dowd, K. (2003), 'PensionMetrics II: Stochastic Pension Plan Design During the Distribution Phase', Insurance, Mathematics and Economics, 33, 2947.

Brown, J. R. (2001), 'Private Pensions, Mortality Risk, and the Decision to Annuitize’, Journal of Public Economics, 82, 29-62.

Campbell, J. Y. and Viceira, L. M. (2002), Strategic Asset Allocation: Portfolio Choice for Long Term Investors, OUP, Oxford. 
Davidoff, T., Brown, J. and Diamond, P. (2005), ‘Annuities and Individual Welfare’, American Economic Review, 95, 573-1590.

DEXX\&R (2006), Retirement Incomes League Tables, Quarterly Statistics, December 2006, DEXX\&R Research, Sydney.

Doyle, S., Mitchell, O. S. and Piggott, J (2004), ‘Annuity Values in Defined Contribution Retirement Systems: Australian and Singapore Compared', Australian Economic Review, 37, 402-16.

Dus, I., Maurer, R. and Mitchell, O. S. (2005), Betting on Death and Capital Markets in Retirement: A Shortfall Risk Analysis of Life Annuities versus Phased Withdrawal Plans, NBER Working Paper No. 11271.

Horneff, W., Maurer, R., Mitchell, O. S. and Dus, I. (2007), ‘Following the Rules: Integrating Asset Allocation and Annuitization in Retirement Portfolios Insurance’, Mathematics and Economics, 1-13.

Kingston, G. and Thorp, S. (2005), 'Annuitization and Asset Allocation with HARA Utility', Journal of Pension Economics and Finance, 4, 225-248. 
Mitchell, O. S., Piggott, J., Sherris, M. and Yow, S (2006), 'Financial Innovation for an Aging World', in Kent, C., Park, A. and Rees, D. (eds), Demography and Financial Markets, Reserve Bank of Australia.

Mitchell, O. S., Poterba, J., Warshawsky, M. J. and Brown, J. R. (1999), ‘New Evidence on the Money’s Worth of Individual Annuities’, American Economic Review 89, 12991318.

Plan for Life Research, The Pension and Annuity Market Research Report, Quarterly 19992007.

Purcal, S. (2006), 'Supply Challenges to the Provision of Annuities’, School of Actuarial Studies, UNSW, Working Paper 2006-14, The University of New South Wales.

Superannuation Industry (Supervision) Amendment Regulations 2007 (No.1), Schedule 3.

Thorp, S., Bateman, H. and Kingston, G. (2007), 'Financial Engineering for Australian Annuitants’, in H. Bateman (ed.), Retirement Provision in Scary Markets, Edward Elgar; 124-148. 


\section{Appendix 1}

\section{Methodology for Construction of Investment Portfolios}

The asset allocations for the five representative investment portfolios are summarized in Table A1.

Table A1

Asset Allocation for Investment Portfolios

\begin{tabular}{lccccc}
\hline $\begin{array}{l}\text { Investment } \\
\text { portfolio }\end{array}$ & $\begin{array}{c}\text { Australian } \\
\text { Shares }\end{array}$ & $\begin{array}{c}\text { International } \\
\text { Shares }\end{array}$ & Property & $\begin{array}{c}\text { Fixed } \\
\text { Interest }\end{array}$ & Cash \\
\hline High Growth & $50 \%$ & $30 \%$ & $10 \%$ & $10 \%$ & $0 \%$ \\
Growth & $37 \%$ & $23 \%$ & $10 \%$ & $28 \%$ & $2 \%$ \\
Balanced & $26 \%$ & $17 \%$ & $7 \%$ & $28 \%$ & $22 \%$ \\
Conservative & $16 \%$ & $10 \%$ & $4 \%$ & $28 \%$ & $42 \%$ \\
Capital Stable & $0 \%$ & $0 \%$ & $0 \%$ & $30 \%$ & $70 \%$ \\
\hline
\end{tabular}

Using monthly observations on asset class returns indices (30 December 1989 - 30 December 2005), we calculate monthly periodic returns and then take a weighted average to make the periodic portfolio return. The net of fees portfolio return is then

$r_{P, t}=\ln \left(1+i_{P, t}\right)-\ln \left(1+f_{P, t}\right)$

Where $i_{P, t}$ is the periodic nominal portfolio return and $f_{P, t}$ is the percentage rate of management fees.

The annualized expected value and volatility of this process are:

$$
\begin{aligned}
& \mu=12 \frac{1}{N} \sum_{n=1}^{N} r_{P, t}+\frac{1}{2} \sigma^{2} \\
& \sigma=s \sqrt{12} \\
& s=\sqrt{\frac{1}{N-1} \sum_{n=1}^{N}\left(r_{P, t}\right)^{2}-\frac{1}{N(N-1)}\left(\sum_{n=1}^{N} r_{P, t}\right)^{2}}
\end{aligned}
$$


where $\mathrm{N}$ is the number of observations in the sample. Table A2 sets out the annualized netof-fees returns and standard deviations for each investment strategy.

Table A2

Portfolio Returns and Volatilities

\begin{tabular}{|lccc|}
\hline Investment Option & $\begin{array}{c}\text { Nominal Rate } \\
\text { of Return }\end{array}$ & $\begin{array}{c}\text { Nominal } \\
\text { Return less } \\
\text { fees }\end{array}$ & Std. Deviation \\
\hline High Growth & $10.4 \%$ & $8.50 \%$ & $9.88 \%$ \\
Growth & $10.0 \%$ & $8.20 \%$ & $7.90 \%$ \\
Balanced & $9.2 \%$ & $7.50 \%$ & $5.82 \%$ \\
Conservative & $8.5 \%$ & $6.80 \%$ & $3.80 \%$ \\
Capital Stable & $7.5 \%$ & $5.90 \%$ & $1.50 \%$ \\
\hline
\end{tabular}

Notes: This table presents estimates of nominal returns and standard deviation values for five representative investment portfolios. Returns are the annualized log change in the weighted sum of monthly periodic returns to the component asset classes, less a deduction for management fees. (Weights for each portfolio are given in Figure 1.) We compute monthly gross returns to each asset class index where Australian equities are the Australia-DS Market index, International equities are the AC WORLD INDEX ex AUSTRALIA translated into Australian dollars at the end-month AUD/USD exchange rate, fixed income is the UBS Composite All Maturities index for Australia, property is the S\&P/ASX 300 Property index and cash is the UBS AU Bank Bills All Maturities index, all from Datastream. The total return price index (RI) of the relevant asset class index was used for calculations of the periodic monthly returns. Sample data runs monthly from December 1989 December 2005

The sample period from which these returns are calculated includes a long period of strong performance in the domestic equity and property markets, which may slightly favour selfinsurance over annuitisation in our analysis since annuity payouts are dependent on returns from fixed interest securities. Notwithstanding some possible overstatement of investment returns, if we condition on a specific allocation, comparisons between alternative draw-down paths and the regulated minimum are valid. 


\section{TABLE 1}

\section{Taxation and Age Pension Means Test Treatment of Retirement Income Streams from a}

\section{Taxed Superannuation Fund}

\begin{tabular}{|c|c|c|c|c|}
\hline \multirow[b]{2}{*}{ Product type } & \multicolumn{2}{|c|}{ Income streams purchased pre 2007} & \multicolumn{2}{|c|}{ Income streams purchased post 2007} \\
\hline & Taxation & Means tests & Taxation & Means tests \\
\hline $\begin{array}{l}\text { Life pension or annuity } \\
\text { Life expectancy pension } \\
\text { or annuity } \\
\text { Term allocated pension } \\
\text { (TAP) }\end{array}$ & $\begin{array}{l}\text { Taxable income } \\
\text { adjusted for annual } \\
\text { deductible amount }{ }^{\text {a }} \\
\text { Earnings on underlying } \\
\text { assets tax exempt }\end{array}$ & $\begin{array}{l}50 \% \text { assets test } \\
\text { exemption }{ }^{\mathrm{b} c} \\
\text { Income adjusted for } \\
\text { return of capital }\end{array}$ & & \\
\hline $\begin{array}{l}\text { Allocated pension or } \\
\text { annuity }\end{array}$ & $\begin{array}{l}\text { Taxable income } \\
\text { adjusted for annual } \\
\text { deductible amount }{ }^{\text {a }} \\
\text { Earnings on underlying } \\
\text { assets tax exempt }\end{array}$ & $\begin{array}{l}\text { Full assets test } \\
\text { applies }\end{array}$ & $\begin{array}{l}\text { Benefits tax } \\
\text { exempt } \\
\text { Earnings on } \\
\text { underlying assets } \\
\text { tax exempt if }\end{array}$ & $\begin{array}{l}\text { Assets test: } \\
\text { Full assets test } \\
\text { applies } \\
\text { Income test: }\end{array}$ \\
\hline $\begin{array}{l}\text { Other term annuity (> } 5 \\
\text { years) }\end{array}$ & $\begin{array}{l}\text { Taxable income } \\
\text { adjusted for annual } \\
\text { deductible amount } \\
\text { Earnings on underlying } \\
\text { assets taxed }\end{array}$ & $\begin{array}{l}\text { Income adjusted for } \\
\text { return of capital }\end{array}$ & $\begin{array}{l}\text { satisfy minimum } \\
\text { standards }\end{array}$ & $\begin{array}{l}\text { Income adjusted } \\
\text { for return of capital }\end{array}$ \\
\hline
\end{tabular}

Source: Bateman and Kingston (2007).

a. Annual deductible amount = undeducted purchase price (UPP)/life expectancy (or term).

b. Asset test taper: \$3 per fortnight for every $\$ 1,000$ of assets above assets test free area.

c. $100 \%$ assets test exemption if purchased before 20 September 2004 .

d. Earnings on underlying assets taxed at 15 per cent for pensions which do not satisfy the 'minimum standards'

e. Assets test taper halved to $\$ 1.50$ per fortnight for every $\$ 1,000$ of assets above assets free area. Applies to assets purchased on or after 20 September 2007 
TABLE 2

Minimum Drawdown by Age under Simplified Superannuation

Age per cent of account balance

$\begin{array}{lc}\text { under age } 65 & 4 \\ 65-74 & 5 \\ 75-79 & 6 \\ 80-84 & 7 \\ 85-89 & 9 \\ 90-94 & 11 \\ 95 \text { and over } & 14\end{array}$

Source: Superannuation Industry (Supervision) Amendment Regulations 2007 (No.1), Schedule 3. 


\section{FIGURE 1}

Market Share: New Purchases of Retirement Income Streams (1999-2007)

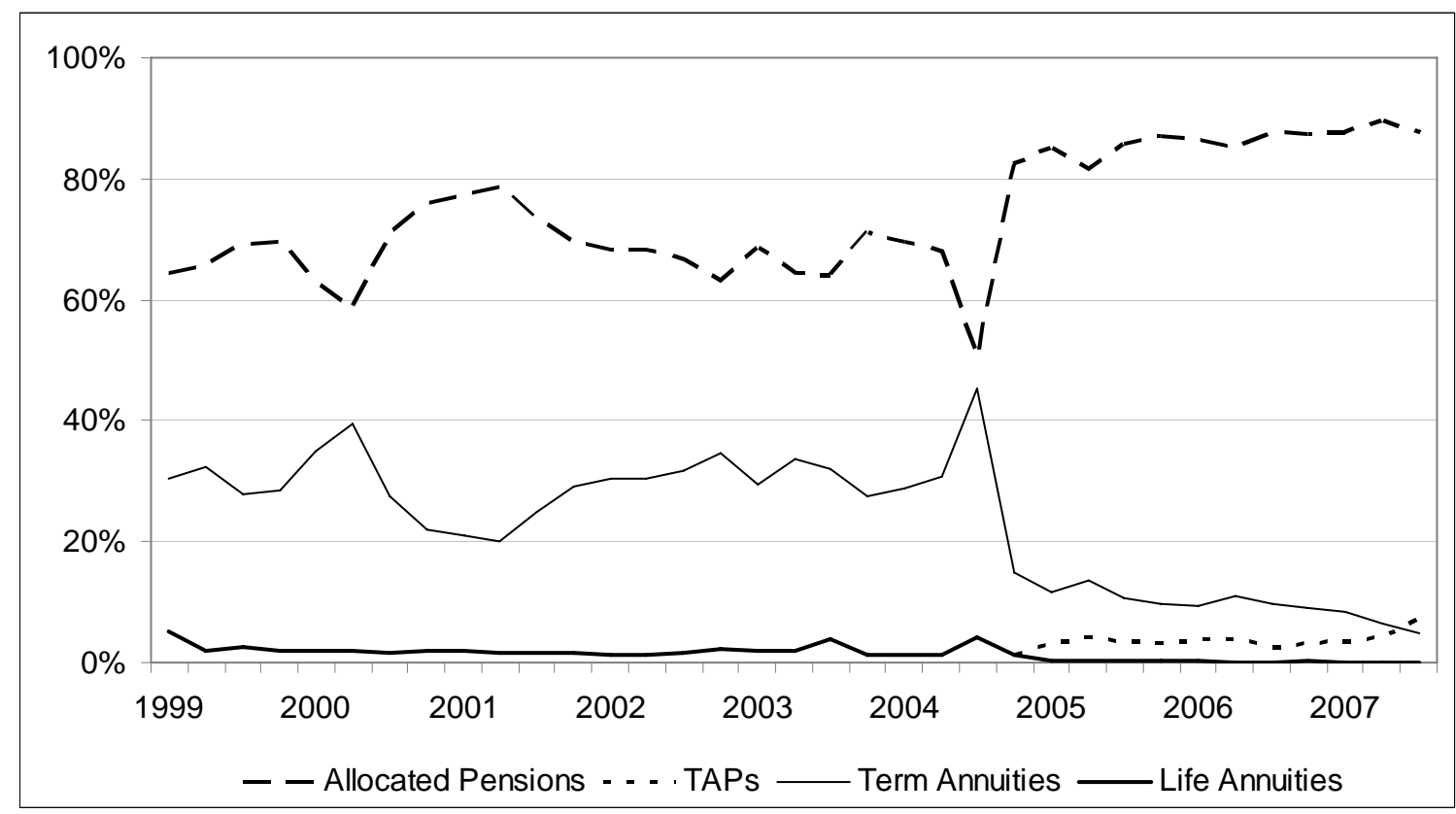

Source: Plan for Life Research, The Pension and Annuity Market Research Report, Quarterly 1999-2007 


\section{FIGURE 2}

\section{Benefit to Wealth Paths under Alternative Drawdown Rules}

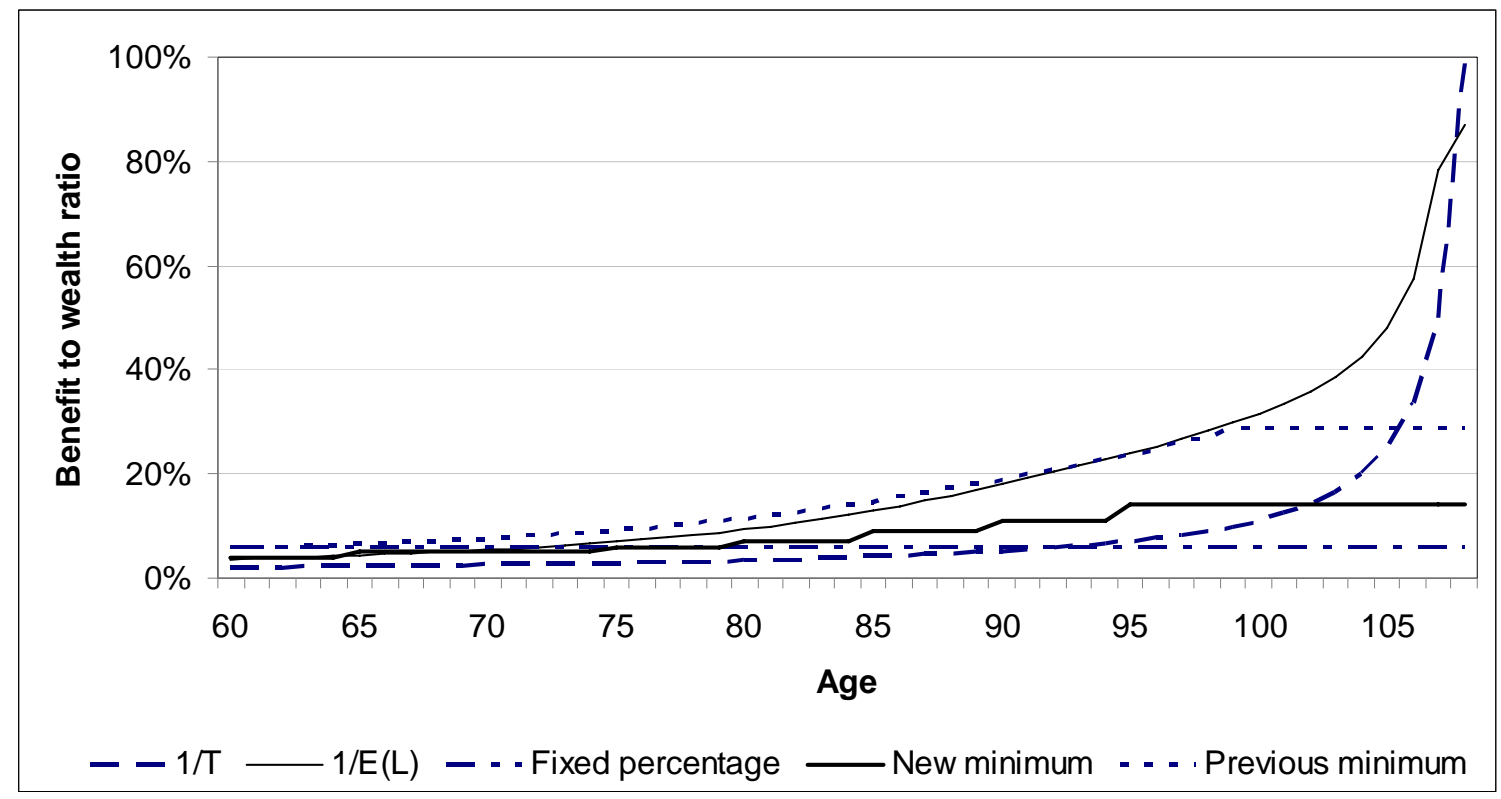




\section{FIGURE 3}

Expected Benefit as a Proportion of the Benchmark Annuity Payment, under Alternative Drawdown Rules

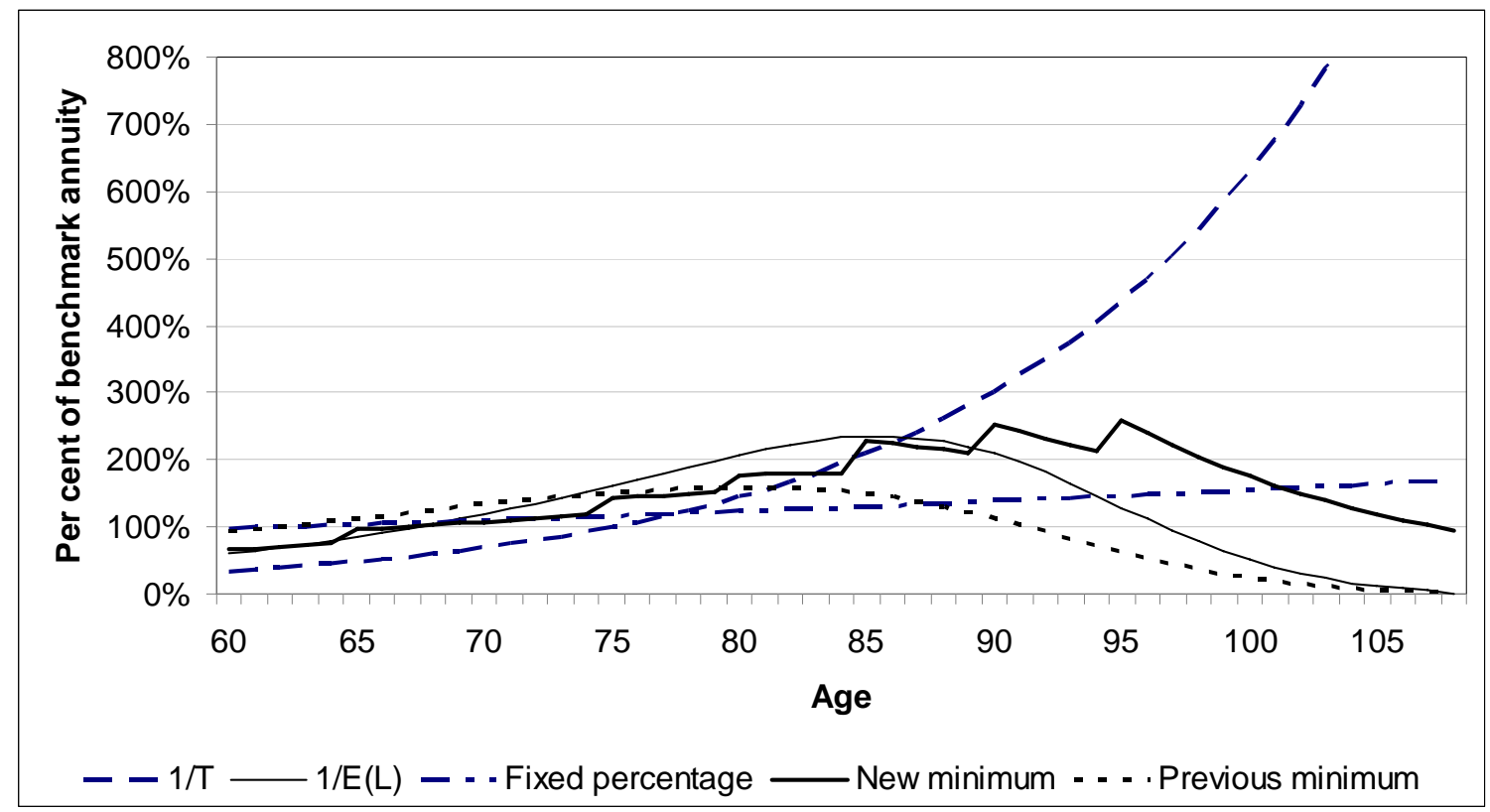




\section{FIGURE 4}

Expected Benefit from Simplified Superannuation as a Proportion of Benchmark Annuity Payment, under Alternative Portfolio Allocations

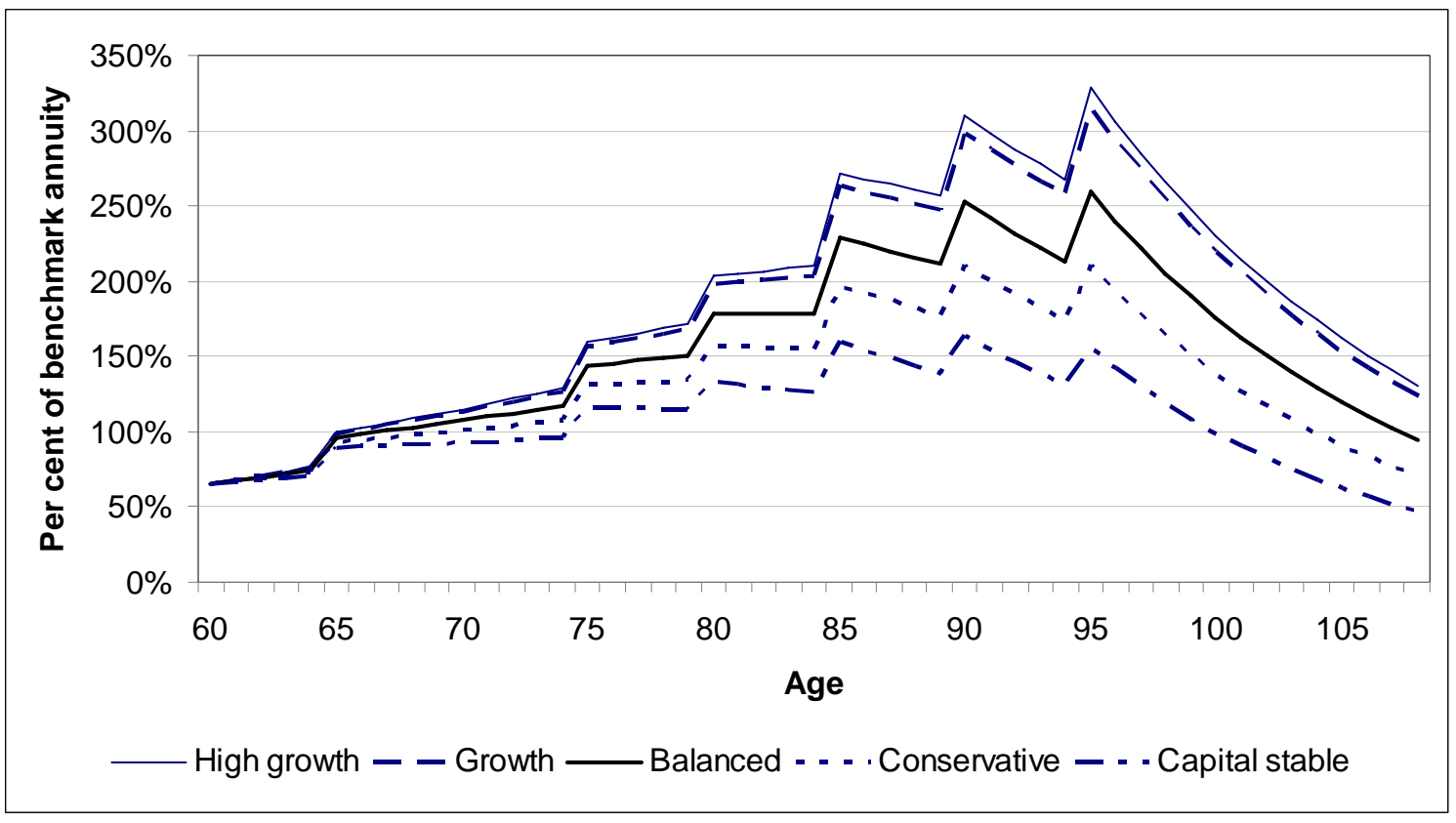




\section{FIGURE 5}

Probable Minimum Benefit as Proportion of Benchmark Annuity Payment, under Alternative Drawdown Rules

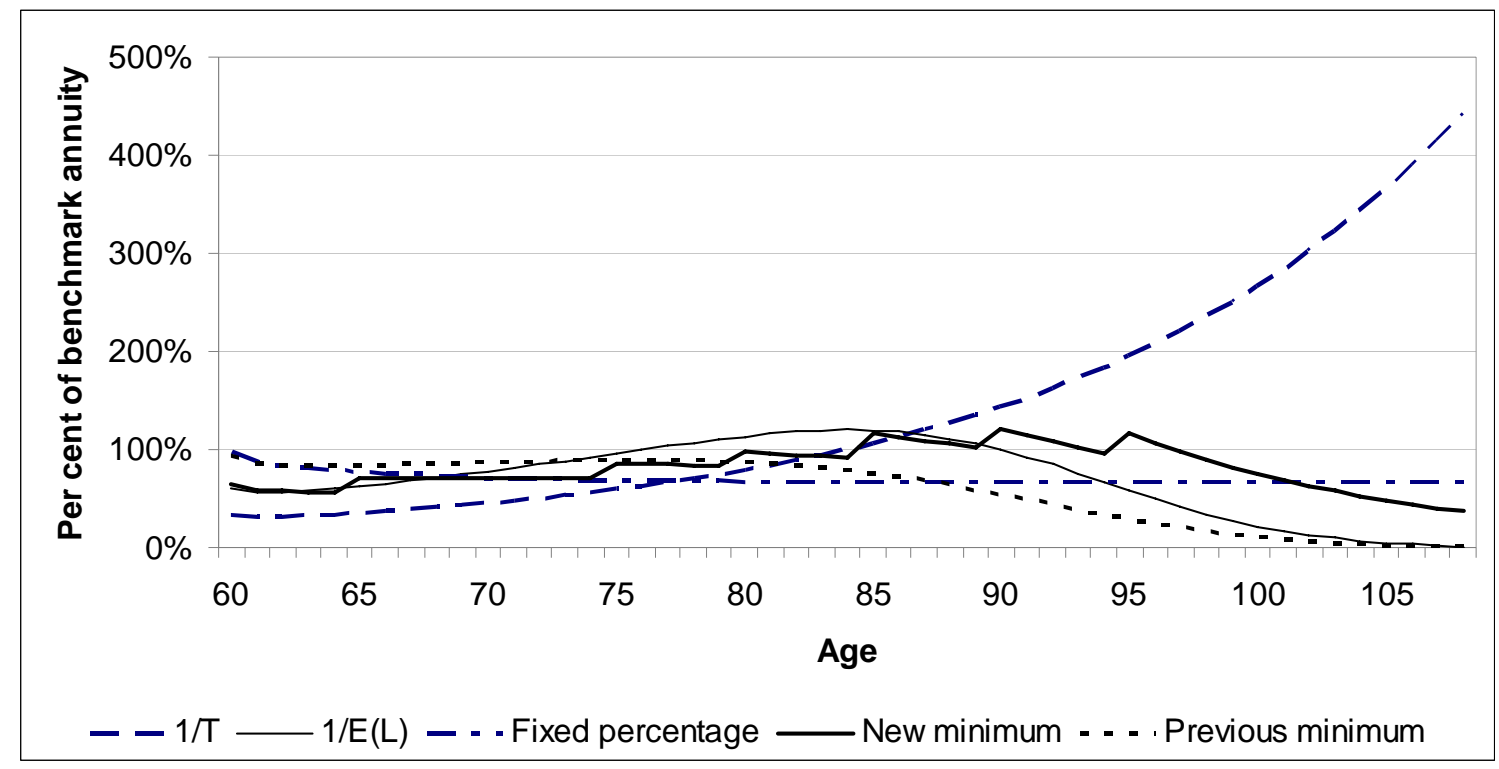




\section{FIGURE 6}

\section{Comparison of Drawdown Rules for a Range of Risk Tolerances}

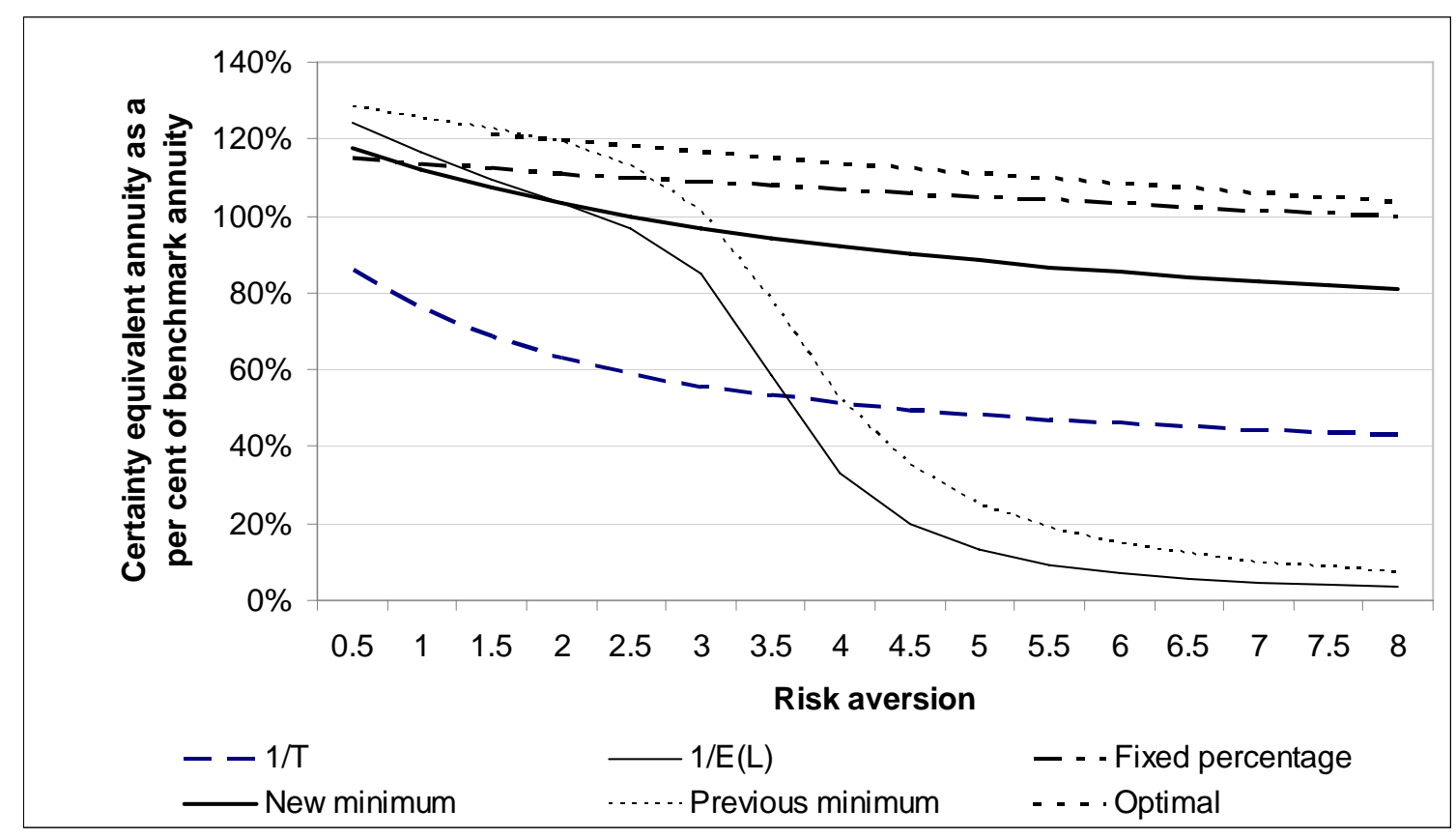




\section{FIGURE 7}

\section{Comparison of Constrained with Unconstrained Drawdown Rules}

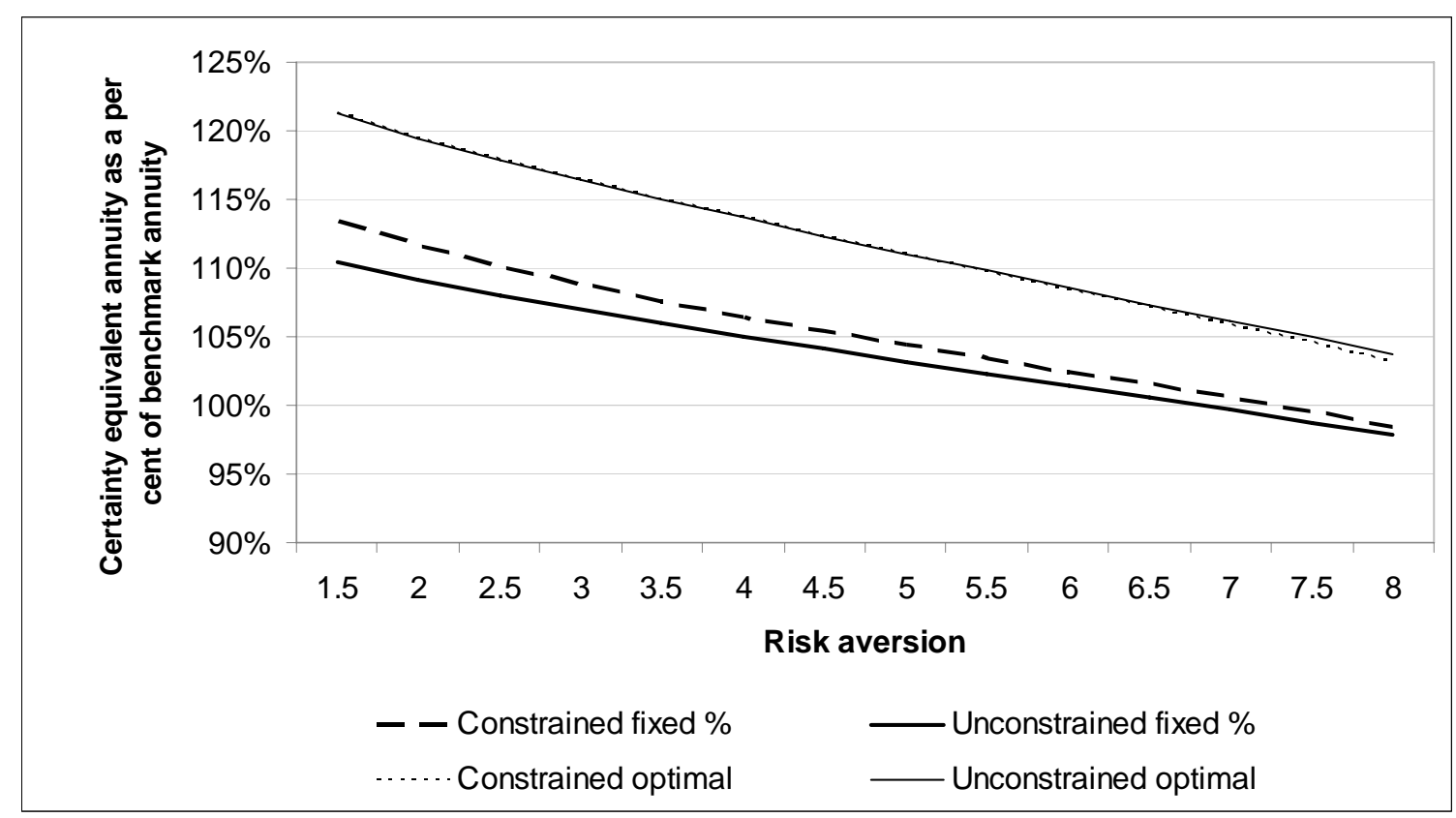




\section{FIGURE 8}

\section{Comparison of Actual and Implied Drawdown Rules}

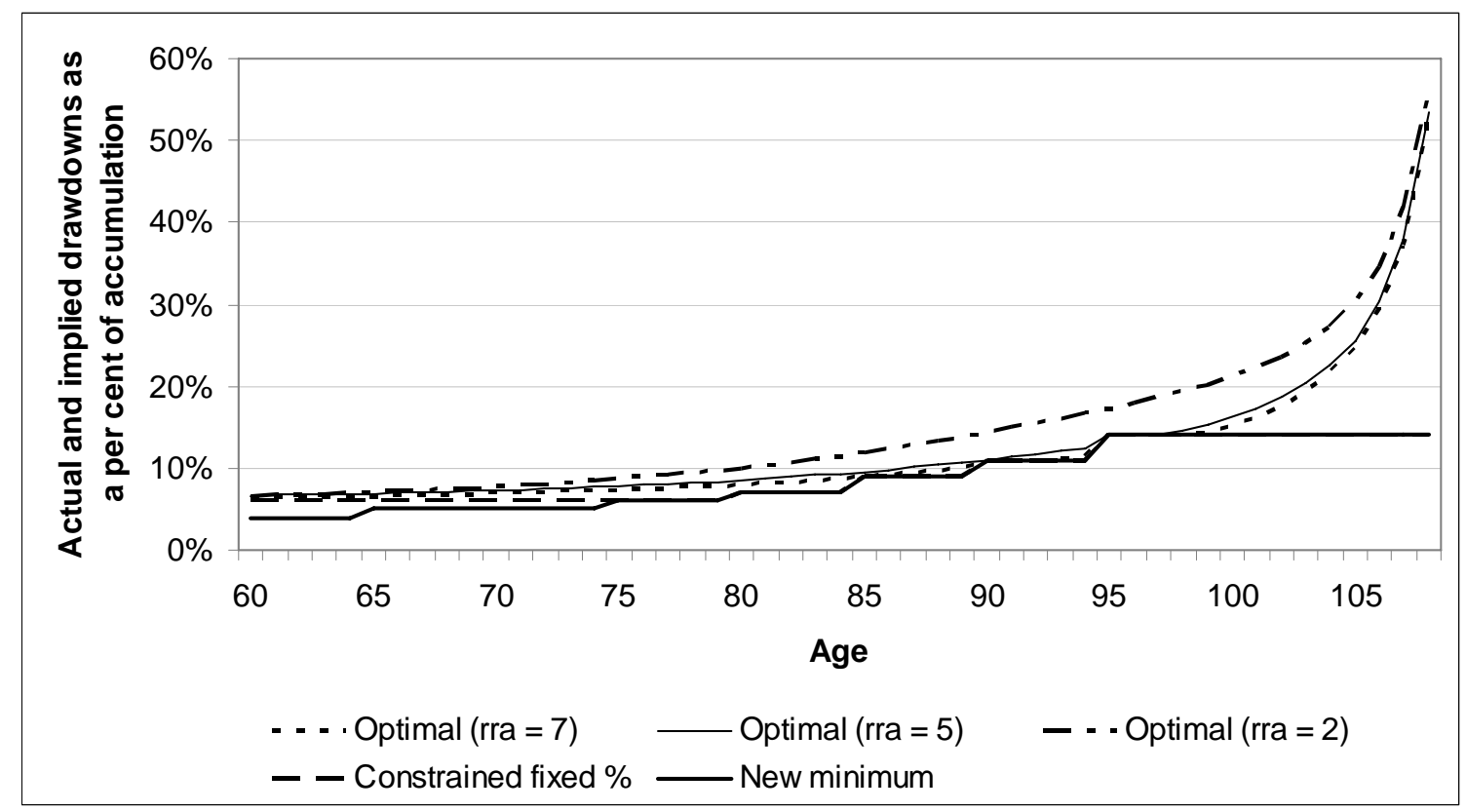


${ }^{1}$ This is despite a growing literature on annuities and retirement payments. See for example Mitchell et al (1999), Brown (2001), Doyle et al. (2002), Davidoff et al. (2005), Dus et al. (2005), Kingston and Thorp (2005), Horneff et al. (2007) and Mitchell et al. (2006).

${ }^{2}$ Subsequently marketed to the Australian public as Better Superannuation.

${ }^{3}$ Where the benefits are paid from a taxed superannuation fund (that is, where deductible contributions to, and investment earnings of, the fund are subject to tax). This represents the vast majority of superannuation funds. Untaxed funds comprise some 'constitutionally protected' public sector funds.

${ }^{4}$ See the seminal paper by Merton (1971), and Campbell and Viceira (2002) for a more recent survey.

${ }^{5}$ An allocated pension is periodic drawdown from a retirement accumulation.

${ }^{6}$ The maximum payments were designed to exhaust the account balance by age 80 , while the minimum payments were designed to last until past 100 years of age.

${ }^{7}$ See Thorp, Kingston and Bateman (2007) for a description of the product features.

${ }^{8}$ In 2006-07 the pension RBL was \$1 356,291, or twice the lump sum RBL of \$678 149.

${ }^{9}$ Allocated pension is defined to include allocated annuities.

${ }^{10}$ Whose benefits are paid from a taxed superannuation fund.

${ }^{11}$ However, the annual drawdown can be greater than the minimum, the aggregate amounts drawn down each year can vary and additional withdrawals can be made at any time.

${ }^{12}$ An exception is 'transition to retirement' pensions which are subject to a 10 per cent maximum drawdown.

${ }^{13}$ The formula-based payout rules used here were also used in Horneff et al. (2007) as the basis for their comparative analysis styled on policy and industry experience in the US and Germany, neither of which have statutory drawdown requirements.

${ }^{14}$ The minimum and maximum pension valuation factors by age are set out in the Superannuation Industry (Supervision) Amendment Regulations. We focus on the minimum drawdown regulations.

${ }^{15}$ The life expectancies are based on improved survival probabilities from the 2002 Australian Life Tables. Improved life expectancies for retirees are computed by decreasing the current conditional probability of dying at each age using a pre-set factor provided in the Life Tables by the Australian Government Actuary and then re-computing the expected remaining lifetime. The 25 year improvement factors used here are designed to project trends to longer life expectancy out over the next 25 years, e.g,. to calculate the life expectancy of a male or female reaching age 80 in 2027. There is considerable uncertainty in forecasting mortality, but here we treat the probability of survival as known.

${ }^{16}$ The annuity payouts are the average of current annuity quotes for a single life annuity with no guarantee, purchased with a premium of $\$ 100000$. These are $\$ 6110$ for males and $\$ 6000 \mathrm{for}$ females. As a result, the benefit/wealth ratios assumed for the fixed percentage rule translate to 6.1 per cent for males and 6.0 per cent for females (see DEXX\&R 2007 for the annuity quotes).

${ }^{17}$ See the HESTA website at www.hesta.com.au for the menu of investment options.

${ }^{18}$ While all benefits are now tax free, the earnings on the underlying assets are only tax free where the minimum standards are met.

${ }^{19}$ We assume that portfolio returns are log-normally distributed in choosing the $1 \%$ quantile. 
${ }^{20}$ It is noted, however, that if the retiree were still alive, she would receive an annual drawdown of at least this minimum payout with a probability of 99 per cent.

${ }^{21}$ As noted earlier, the life expectancies are computed as the 25 year improved survival probabilities from age 10 to 110 from the 2002 Australian Life Tables.

${ }^{22}$ As indicated in Horneff et al. 2007, $\gamma$ below 1 represents low risk aversion, $\gamma$ of between 1 and 5 represents moderate risk aversion, while $\gamma$ above 5 represents high risk aversion.

${ }^{23}$ See Horneff et al. 2007 for a detailed description of the dynamic programming problem. Solutions presented here are derived numerically using optimization routines in Matlab.

${ }^{24}$ As has been shown in previous studies (Brown 2001, Horneff et al. 2007).

${ }^{25}$ Similar results were found for male retirees. 